\title{
A Scoping Review of Emerging and Established Surgical Robotic Platforms With Applications in Urologic Surgery
}

\author{
Braden Millan, ${ }^{1}$ Shavy Nagpal, ${ }^{1}$ Maylynn Ding, ${ }^{1}$ Jason Y. Lee, ${ }^{2}$ Anil Kapoor ${ }^{\bigotimes 1}$ \\ ${ }^{1}$ Urologic Cancer Centre for Research and Innovation (UCCRI), McMaster University, Hamilton, Canada \\ ${ }^{2}$ Department of Surgery, Division of Urology, University of Toronto, Canada
}

\section{Abstract}

Objectives Since the introduction of the first master-slave robotic platform for surgical procedures, there have been ongoing modifications and development of new platforms, but there is still a paucity of commercially available systems. Our study aims to identify all master-slave robotic surgical platforms currently commercially available or in development around the world with applications in urologic surgery.

Methods A scoping literature search was performed using PRISMA methodology to identify all relevant publications in English in PubMed, PubMed Central, and Embase, with additional information being obtained from official company websites.

Results Ten robotic platforms with either proven or potential application in urologic surgery were identified: the da Vinci surgical system (Intuitive), Senhance surgical system (Transentrix), Versius Surgical (CMR Ltd), Enos surgical system (Titan Medical), Revo -I (Meere Company), MiroSurge (DLR), Avatera System (Avatera Medical), Hugo Surgical Robot (Medtronic), Ottava (J\&J, Ethicon, Areus), and Hinotori (Medicaroid Corporation).

Conclusions This review highlights the distinct features of emerging master-slave robotic platforms with applications in urologic surgery. Research and development are now focused on finding wider applications, improving outcomes, increasing availability, and reducing cost. Additional research is required comparing newly developed master-slave robotic platforms with those already well established.

Key Words

Robot-assisted surgery, laparoscopy, robotics, urology
Competing Interests

None declared.

\section{Article Information}

Received on October 6, 2020

Accepted on June 1, 2021

Soc Int Urol J.2021;2(5):300-310

DOI: 10.48083/EWW02677 


\section{Abbreviations}

DOF degrees of freedom

HD high definition

LESS laparoendoscopic single-site surgery

MIS minimally invasive surgery

N/A not available

\section{Introduction}

The field of urology has played a major role in the advancement of surgical robotics, dating back to the MONA robot, the prototype of the modern day da Vinci surgical robot[1]. The most advanced surgical robotic platforms currently are the "master-slave systems" in which the surgeon controls robotic arms remotely from a console. In a dry laboratory setting, Choussein and colleagues were able to demonstrate that robot-assisted laparoscopy nearly eliminated operative handedness, which persists in conventional laparoscopy[2]. Robotic platforms can be categorized by some of their key features, and there are many similarities amongst them. One major distinction is the open versus the closed robotic platform console. In an open console, there is no ability for the operator to fix his or her head in position; instead, the head can be moved freely during the procedure. These alterations in the field of view from the display during an operation can result in errors and decreased efficiency[3]. A development in newer generations of robotic platforms is the addition of haptic feedback from the robot for the operating physician. Abiri and colleagues tested a multi-modal system for haptic force feedback in robotic surgery that results in nearly a $50 \%$ force reduction in comparison to a system with no haptic feedback[4].

Laparoendoscopic single-site surgery (LESS) is another feature of surgical robotic platforms that is an advancement from original laparoscopy. One disadvantage of LESS is the challenge of instruments interfering with one another, although early success has been reported[5-7]. No head-to-head comparison of any robotic platforms from different companies exists in the urologic literature. This paper provides a scoping review on established and emerging master-slave robotic platforms in urologic surgery.

\section{Methods}

In the absence of a clear population, intervention, comparison, and outcome research question, we elected to perform a systematic scoping review of the currently available literature on this topic[8]. The goal of this article is not to compare surgical or oncologic outcomes of procedures performed with the different robotic platforms, but to highlight the emerging technologies in robotic platforms. Three databases were searched for articles published in English. PubMed and PubMed Central ( $\mathrm{n}=3644$ ) were searched using the following terms: "robotic surgical procedures," "robotics," "urology," "urology department, hospital," "urologic surgical procedures," "urologic surgical procedures, male." Embase $(n=3252)$ was searched using the following terms: "robot," "robotics," "robotic surgical procedures," "robot assisted surgery," "urology," "child urology," "urologic surgery." Additional records were identified through screening the citations of selected texts $(n=20$; Figure 1). Additional information was obtained by searching through google.com (Google Inc, Mountain View, United States) and official company websites $(\mathrm{n}=9)$. All case reports, case series, cohort studies, and randomized controlled trials written in English were included. Articles were excluded if they were abstracts, editorials, expert opinions, or review articles, if they did not report the surgical platform used, or if the platform has been discontinued. Preferred reporting items for systematic reviews and metaanalyses (PRISMA) guidelines were used to ensure reproducibility of our scoping review[9].

\section{Results}

After initial screening of titles, 57 articles underwent final review, and 41 articles were included in the final paper (Figure 1)[10]. A total of 10 master-slave surgical robots were identified through our scoping systematic review. For each surgical platform we sought to provide information regarding the current company with proprietary rights to the device, whether or not it had regulatory approval, the main features of the robotic platform, and a review of any pre-clinical or clinical data (Table 1). A summary of the major features of each system is shown in Table 2.

\section{da Vinci Surgical System}

The da Vinci surgical system is a master-slave laparoscopic robotic platform, designed and owned by Intuitive Surgical (Sunnyvale, United States) (Figure 2). It has played a crucial role in enhancing minimally invasive surgery and was Food and Drug Administration (FDA) approved in the year 1998, originally for laparoscopic cholecystectomies, and received the Conformitè Europëenne (CE) mark in 2017. One of its early competitors, Zeus (Computer Motion), was discontinued following the company's merger with Intuitive Surgical in 2003. Iterations of the da Vinci have been in use for over 2 decades, and its applications include general, cardiac, colorectal, otolaryngology, neurosurgery, thoracic, gynecologic and urologic surgery. Its features include a 3-dimensional (3-D) highdefinition (HD) camera with a binocular view, and 


\section{FIGURE 1.}

PRISMA flow diagram[10]

\section{Identification of studies via databases and registers}

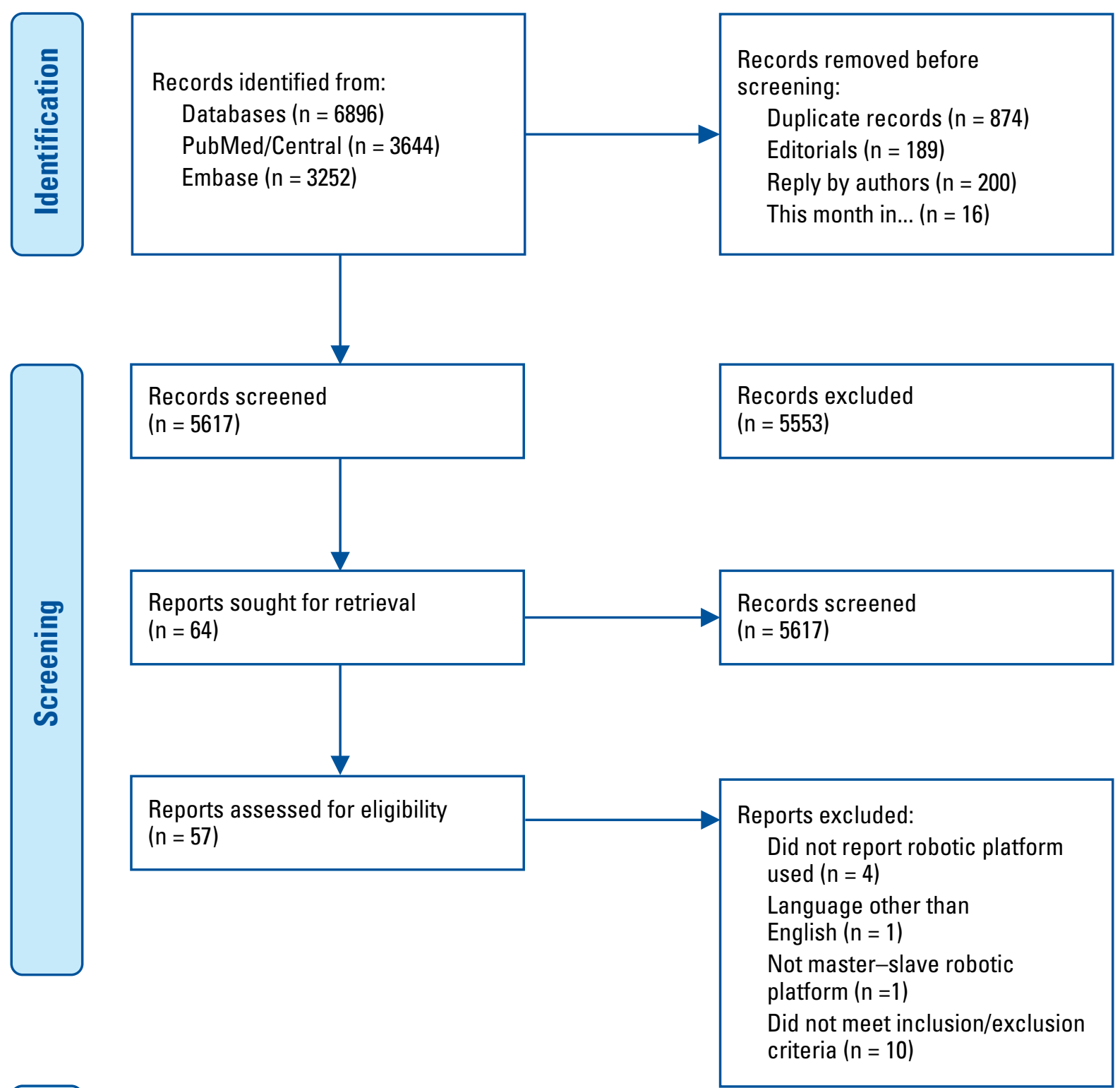

Studies included in review $(n=41)$ 


\section{TABLE 1.}

Emerging and currently available master-slave robotic platforms with applications in urologic surgery

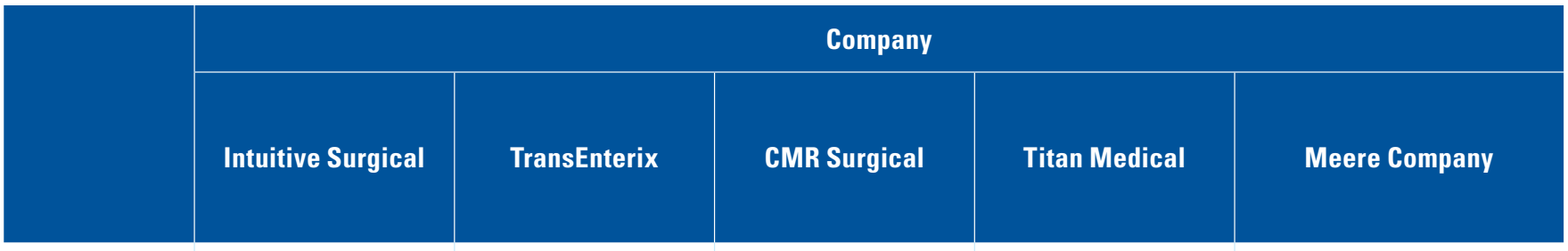

Robotic

Platform $\quad(\mathrm{Si}, \mathrm{X}, \mathrm{Xi}$, and SP

Da Vinci

Senhance

Versius

Enos $^{* *}$

Revo - i

\begin{tabular}{|l|l|l|l|l|l|}
\hline Headquarters & United States & United States & United Kingdom & Canada & Republic of Korea \\
\hline Approach & Laparoscopic, LESS & Laparoscopic & Laparoscopic & LESS & Laparaoscopic \\
\hline
\end{tabular}

\begin{tabular}{|c|c|c|c|c|c|}
\hline $\begin{array}{l}\text { Advertised } \\
\text { Application }\end{array}$ & $\begin{array}{l}\text { Urology, Gynecology, } \\
\text { General Surgery, \& } \\
\text { Otolaryngology }\end{array}$ & $\begin{array}{c}\text { Urology, } \\
\text { Gynecology, General, } \\
\text { Colorectal \& } \\
\text { Limited Cardiothoracic } \\
\text { Surgery }\end{array}$ & $\begin{array}{l}\text { Urology, } \\
\text { Gynecology, } \\
\text { Colorectal \& } \\
\text { Upper Gl }\end{array}$ & $\begin{array}{l}\text { Urology, } \\
\text { General Surgery }\end{array}$ & $\begin{array}{c}\text { Urology, } \\
\text { Gynecology \& } \\
\text { General Surgery }\end{array}$ \\
\hline Status & $\begin{array}{l}\text { Commercially } \\
\text { available }\end{array}$ & $\begin{array}{c}\text { Commercially } \\
\text { available }\end{array}$ & $\begin{array}{c}\text { Commercially } \\
\text { available }\end{array}$ & Under development & Commercially available \\
\hline $\begin{array}{l}\text { Regulatory } \\
\text { Approval }\end{array}$ & $\begin{array}{c}\text { FDA approved (1998) } \\
\text { European CE Mark } \\
\text { (2017) }\end{array}$ & $\begin{array}{c}\text { FDA approved (2017) } \\
\text { European CE Mark } \\
\text { (2016) }\end{array}$ & $\begin{array}{c}\text { European CE } \\
\text { Mark (2019) } \\
\text { TGA approval } \\
\text { (2020) }\end{array}$ & Not approved & $\begin{array}{c}\text { Korean Ministry for } \\
\text { Drug and Food Safety } \\
\text { (2019) }\end{array}$ \\
\hline
\end{tabular}

\section{Maximum}

number of

Robotic Arms

\section{Degrees of}

Freedom

4

4

5

1

4

\begin{tabular}{|c|c|c|c|c|c|}
\hline \\
\hline Console & Seated, Closed & Seated, Open & $\begin{array}{l}\text { Seated/standing, } \\
\text { Open (3D glasses) }\end{array}$ & Seated, Open & Seated, Open \\
\hline Camera & $H D-3 D$ & $H D-3 D$ & $H D-3 D$ & $H D-3 D$ & $H D-3 D$ \\
\hline $\begin{array}{l}\text { Haptic } \\
\text { Feedback }\end{array}$ & No & Yes & Yes & No & Yes \\
\hline
\end{tabular}

LESS: laparoendoscopic single site surgery; GI: gastrointestinal; N/A :not available; HD-3D: high definition three dimensional; FDA: US Food and Drug Administration; TGA: Therapeutic Goods Administration (Australia); CE: Conformitè Europëenne; * previously the Verb and Auris robotic platform; **Rebranded from the single port orifice robotic technology (SPORT) surgical system 
TABLE 1.

Emerging and currently available master-slave robotic platforms with applications in urologic surgery, Cont'd

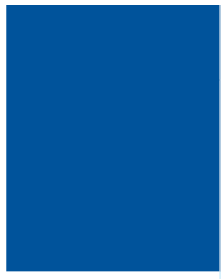

\begin{tabular}{|c|c|c|c|}
\hline \multicolumn{4}{|c|}{ Company } \\
\hline $\begin{array}{c}\text { Robotics and } \\
\text { Mechatronics Center } \\
\text { at German Aerospace } \\
\text { Center (DLR) }\end{array}$ & $\begin{array}{c}\text { Avatera } \\
\text { Medical }\end{array}$ & Medtronic & $\begin{array}{c}\text { Johnson \& } \\
\text { Johnson/ } \\
\text { Ethicon/Verily }\end{array}$ \\
\hline
\end{tabular}

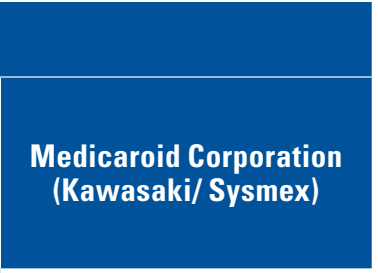

\section{Robotic}

Platform

DLR MiroSurg

Avatera

Hugo

Ottava*

Hinotori

\begin{tabular}{|l|l|l|l|l|}
\hline Headquarters & Germany & Germany & Ireland & United States \\
\hline
\end{tabular}

\begin{tabular}{|c|c|}
\hline Approach & Ian $x+3$ \\
\hline
\end{tabular}

\begin{tabular}{|l|c|c|c|c|}
\hline $\begin{array}{l}\text { Advertised } \\
\text { Application }\end{array}$ & $\begin{array}{c}\text { Urology, General \& } \\
\text { Thoracic surgery }\end{array}$ & $\begin{array}{c}\text { Urology \& } \\
\text { gynecology }\end{array}$ & $\begin{array}{c}\text { Urology, Baratric, } \\
\text { Colorectal \& } \\
\text { Thoracic Surgery }\end{array}$ & N/A
\end{tabular}

\section{Maximum}

number of

Robotic Arms

\begin{tabular}{|c|c|c|c|c|c|}
\hline $\begin{array}{l}\text { Degrees of } \\
\text { Freedom }\end{array}$ & 3 & 7 & 7 & $\mathrm{~N} / \mathrm{A}$ & 8 \\
\hline Console & $\begin{array}{r}\text { Seated, Open } \\
\text { (3D glasses) }\end{array}$ & $\begin{array}{l}\text { Seated, } \\
\text { Closed }\end{array}$ & $\begin{array}{l}\text { Seated, } \\
\text { Semi-Open } \\
\text { (3D glasses) }\end{array}$ & $\mathrm{N} / \mathrm{A}$ & $\begin{array}{l}\text { Seated, Semi-Open } \\
\text { (polarized glasses) }\end{array}$ \\
\hline Camera & $H D-3 D$ & $H D-3 D$ & $H D-3 D$ & $\mathrm{~N} / \mathrm{A}$ & $H D-3 D$ \\
\hline $\begin{array}{l}\text { Haptic } \\
\text { Feedback }\end{array}$ & Yes & Yes & $\mathrm{N} / \mathrm{A}$ & $\mathrm{N} / \mathrm{A}$ & N/A \\
\hline
\end{tabular}

LESS: laparoendoscopic single site surgery; Gl: gastrointestinal; N/A :not available; HD-3D: high definition three dimensional; FDA: US Food and Drug Administration; TGA: Therapeutic Goods Administration (Australia); CE: Conformitè Europëenne; * previously the Verb and Auris robotic platform; **Rebranded from the single port orifice robotic technology (SPORT) surgical system 


\section{TABLE 2.}

Summary of major features of identified master-slave robotic platforms

Feature
\begin{tabular}{c|l} 
Degrees of freedom \\
\hline 6 & Enos \\
\hline 7 & $\begin{array}{l}\text { Da Vinci, Senhance, Avatera, Hugo, } \\
\text { Versius, MiroSurge }\end{array}$ \\
\hline 8 & Hinotori \\
\hline 12 & Revo-i \\
\hline
\end{tabular}

Approach

\begin{tabular}{|c|c|}
\hline Laparoscopic & $\begin{array}{l}\text { Senhance, Avatera, Hugo, Revo - I, } \\
\text { Versius, MiroSurge, Hinotori }\end{array}$ \\
\hline LESS & Enos \\
\hline Both & Da vinci \\
\hline \multicolumn{2}{|l|}{ Console } \\
\hline Closed & Davinci, Avatera, Revo-i \\
\hline Open & Senhance, Enos, MicroSurge \\
\hline Semi-open & Hugo, Hinotori \\
\hline Semi-closed & Medicaroid \\
\hline Seated/standing-open & Versius \\
\hline \multicolumn{2}{|l|}{ Haptic Feedback } \\
\hline Yes & $\begin{array}{l}\text { Da Vinci, Senhance, Avatera, Revo-I, } \\
\text { Versius, MiroSurge }\end{array}$ \\
\hline No & Enos \\
\hline $\mathrm{N} / \mathrm{A}$ & Hugo, Hinotori \\
\hline
\end{tabular}

LESS: laparoendoscopic single site surgery; N/A: not available; Ottava excluded as details of system unknown

up to 3 instrument arms, which articulate at the wrist of the instrument with 7 degrees of freedom (DOF). There several available series, including the da Vinci $S$, $\mathrm{Si}, \mathrm{X}, \mathrm{Xi}$, and SP (single port), with the newest versions having haptic feedback for the operator. Although modifications are aimed at improvement in currently available technology, reports suggest that changing from one model to another still poses some challenges for the surgeons[11]. However, certain models may be

\section{FIGURE 2.}

da Vinci Surgical System (Credit: Intuitive Surgical)

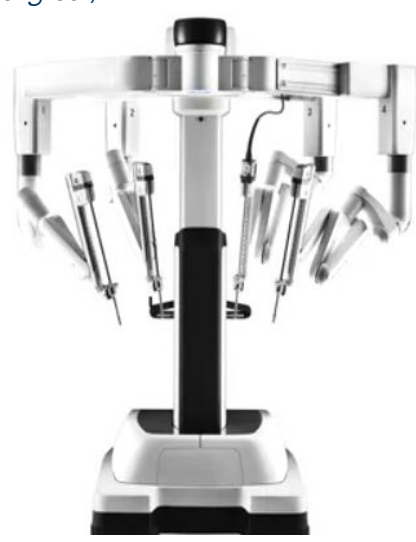

better suited for certain procedures, for example, the $\mathrm{Xi}$ resulted in a 48 minute shorter operative time for nephroureterectomies[12]. Intuitive has also made advances in the field of LESS, where in addition to the SP platform, they have developed software to allow for same-sided hand-eye control of the instruments that enables the surgeon's right hand to control the screen right instrument even though the instrument is in the left robotic arm and vice versa[13]. LESS using the da Vinci SP system allows a smaller incision with superior cosmesis and non-inferior oncologic and surgical outcomes, although there appears to be a great learning curve[6,7,14-17]. Additionally, side docking for urologic procedures has been made possible with the da Vinci S and Si systems, allowing better access to the perineum and the urethra throughout the procedure[18]. Successful use of the da Vinci has been reported for surgeries including radical prostatectomy, simple enucleation of the prostate, radical cystectomy with intra or extra-corporeal ileal conduit or neobladder, radical and simple nephrectomy, live donor nephrectomy, pyeloplasty, adrenalectomy, sural nerve grafting, vaso-vasostomy, ureteral reimplant, and renal transplantation[14,19-25]. In addition to surgery on adults, da Vinci has also been successfully used in pediatrics using $5 \mathrm{~mm}$ instruments as well as a LESS approach with no conversion to open procedure and with high success rates[26,27]. There are few direct comparisons of the costs of robot-assisted laparoscopy in urologic surgery, although previous reports dating back nearly a decade suggested use of the da Vinci surgical platform was more expensive secondary to capital cost, maintenance of the robot, and limited life of the instruments[28]. Intuitive Surgical has grown its da Vinci Surgical System installed base to 6142 systems as of March 31, 2021, an increase of 8\% compared with 5669 as of the end of the first quarter of 2020, continuing its near monopoly on the field of master-slave surgical platforms globally. 


\section{Senhance Surgical System}

The Senhance surgical system is a master-slave robotic platform designed by TransEnterix (Figure 3). It was renamed from the Alf $-\mathrm{X}$ in 2016, developed by SOFAR SpA (Milan, Italy), which was used to perform its first clinical cases in 2015[29,30]. This system and the da Vinci by Intuitive are the 2 master-slave robotic platforms that have both a CE mark (2014) and FDA approval (2017)[31]. Its features include a seated-open concept control centre with haptic handles, a 2-D or 3-D HD monitor, depending on surgeon preference, an infrared eye-tracking system, a keyboard and touch pad, a single pedal, up to 4 detached and independent robotic arms, and reusable $5 \mathrm{~mm}$ endoscopic instruments[32,33]. The major benefit of the open structure is reduced cost, as it allows for use of conventional laparoscopic equipment and operating theaters. Criticisms include a larger size, restricting space in the operating room, and longer time to dock the robotic arms[30]. Plans for the Senhance Surgical System include a "machine vision system," a form of augmented intelligence whereby the system moves the camera on the basis of prior procedures and the movements of the surgeon's instruments. Initial report of the first 40 extra-peritoneal radical prostatectomies performed by Kaštelan et al. showed higher than expected length of hospital stay and indwelling catheter time; however, this was thought to be related to the learning curve of using a new platform[34]. Samalavicius and colleagues performed 31 radical prostatectomies using Senhance, with few complications and no conversion to open procedures[35]. A subsequent case series reported decreases in positive surgical margin rate and lower rates of postoperative incontinence in patients undergoing radical prostatectomy, and expanded the application of the Senhance robotic platform to adrenalectomies, nephrectomy, kidney cyst fenestration, and pyeloplasty with success[36]. The aforementioned developments and clinical data showing the success of the Senhance platform will make it a strong competitor in the field of master-slave surgical robots.

\section{FIGURE 3.}

Senhance Surgical System

(Credit: Asensus Surgical, TransEnterix)

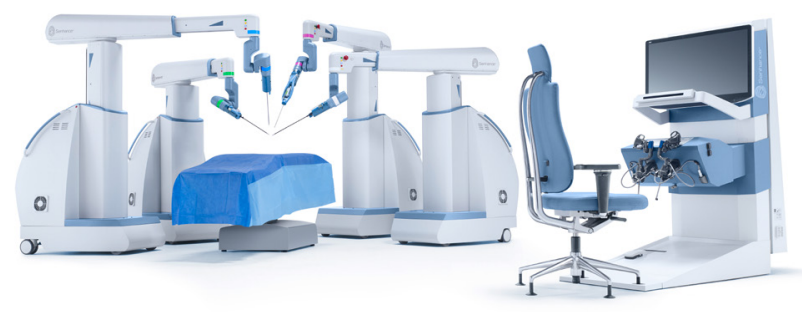

\section{Versius Surgical Robotic System}

The Versius system is a master-slave surgical platform developed by Cambridge Medical Robotics Limited (CMR Ltd) Surgical in the United Kingdom (Figure 4). It received the CE Mark in 2019 and Therapeutic Goods Administration (Australia) approval in 2020. The platform is ergonomic, with an open console that enables both sitting and standing for the operator, with HD-3D visual aid. The surgeon can use up to 5 lightweight robotic arms, each as a solitary robotic unit for greater freedom of port placement. V-wrist technology allows 360-degree wrist motion, 7 DOF, with haptic feedback[37]. Although not performed with the final product, pre-clinical trials using Versius were completed, with a total of 24 surgeries performed (radical nephrectomy, radical prostatectomy, and pelvic lymph node dissection), with no device or non-device intraoperative complications[38]. Human clinical trials using the platform have been limited to gynecologic and general surgery procedures[39].

\section{FIGURE 4.}

Versius Surgical Robotic System (Credit: CMR Surgical)

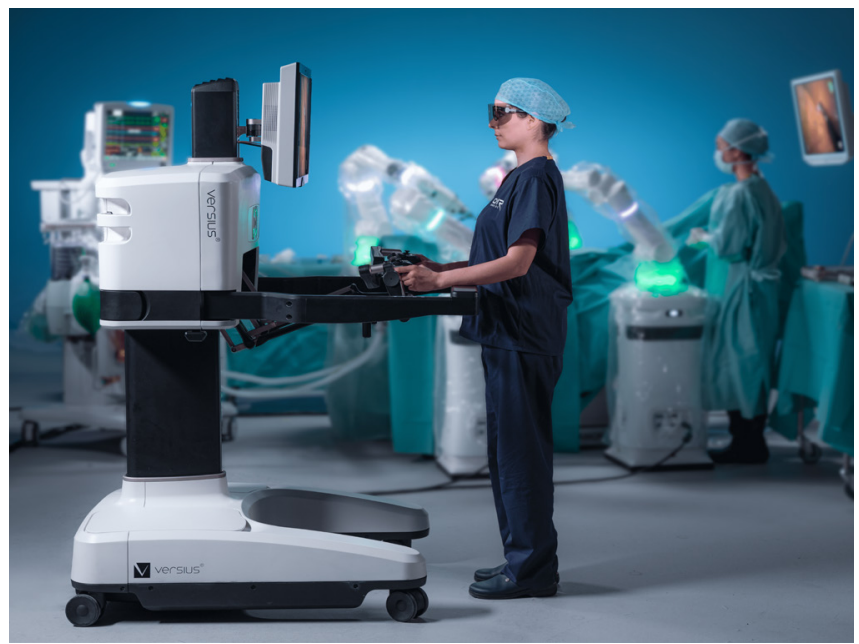

\section{Enos Surgical System}

The Enos surgical system, rebranded in 2020 from the single-port orifice robotic technology (SPORT) surgical system is master-slave robotic platform created by the Canadian company, Titan Medical (Toronto, Canada). Enos does not have FDA approval or CE mark to date. The surgeon workstation is a seated-open design, with 3D-HD visualization. It has a single-arm mobile patient cart to allow for LESS, and a multi-articulating endoscope and instruments that provide 6 DOF. In 2018, Seeliger and colleagues showed promising feasibility and operator improvement with the SPORT platform by 
completing 12 minimally invasive procedures in porcine and human cadaveric pre-clinical trial procedures[5]. There are currently no pre-clinical or clinical data specifically on the Enos platform since it was rebranded.

\section{Revo-I Model MSR-5000}

Meere Company Incorporated, a Korean company, began development on the Revo-I Model MSR-5000, a master-slave robotic surgical platform, in 2006. The Revo-I Model MSR-5000 received approval for commercial use from the Korean government in August 2017, but it has not received FDA or CE Mark to date. The Revo-I Model MSR-5000 (Figure 5) consists of a seated-closed surgeon control console, a 4-arm robotic operation cart, a 3D-HD vision cart, and reusable endoscopic instruments[40,41]. Previous models of the robotic platform had a seated-open surgical console[42]. The Revo-I Model MSR-5000 robotic instruments also offer the greatest flexibility with 12 DOF compared with the 7 DOF built into its contemporaries. Chang and colleagues successfully completed 17 Retziussparing robotic prostatectomy using the Revo-I Model MSR-5000 with no conversion to open or laparoscopic procedures or systems failures. One major limitation of this study, however, was that no pelvic lymph node dissections were performed for fear of intraoperative pelvic vessel injury[41]. Despite these successes, there has not been widespread use of the Revo-I Model MSR5000 outside Korea.

\section{FIGURE 5.}

Revo-I Model MSR-5000

(Credit: Revo-i, robotic surgical system (meerecompany)

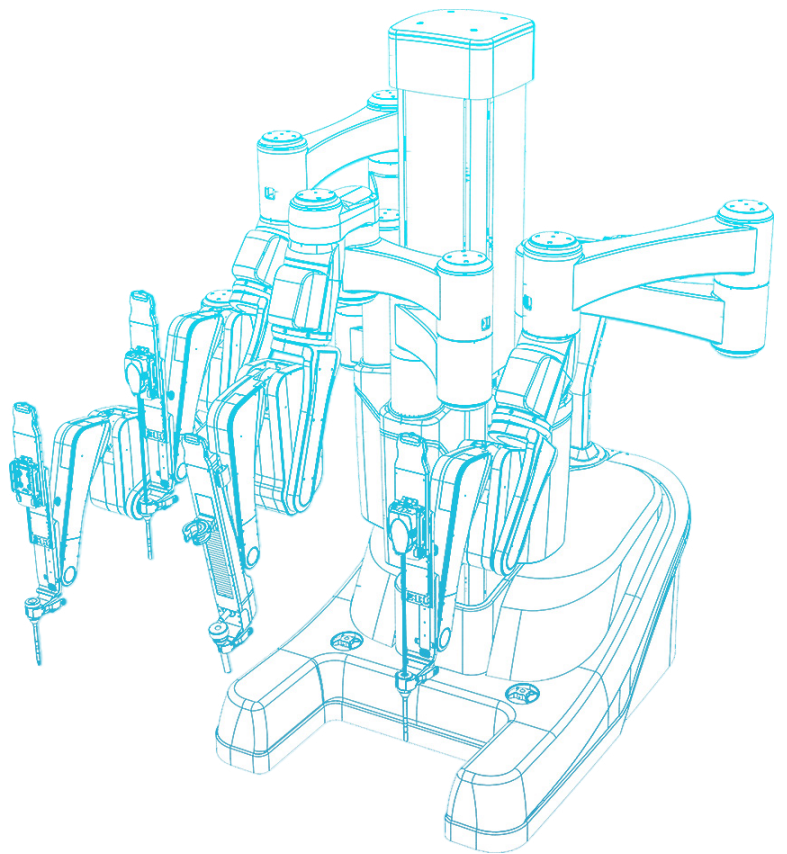

\section{MiroSurge}

The DLR (Deutsches Zentrum für Luft- und Raumfahrt e.V) telesurgery MiroSurge is a master-slave robotic platform made by German Aerospace Center. It currently does not have any regulatory body approval. The DLR MiroSurge (Figure 6) is a modular system that combines several robotic components, including 3 robot arms (DLR MIRO) and at least 2 instruments (DLR MICA). It offers a seated-open console with a 3-D HD video display, with instruments with $3 \mathrm{DOF}$ and haptic feedback. One of the arms guides the laparoscopic view while the video screen updates the status of currently used instruments and prevents collision of instruments via force feedback[43]. No current pre-clinical or clinical data are available; the last publication was in 2011.

\section{FIGURE 6.}

MiroSurge

(Credit: MiroSurge, German Aerospace Center)

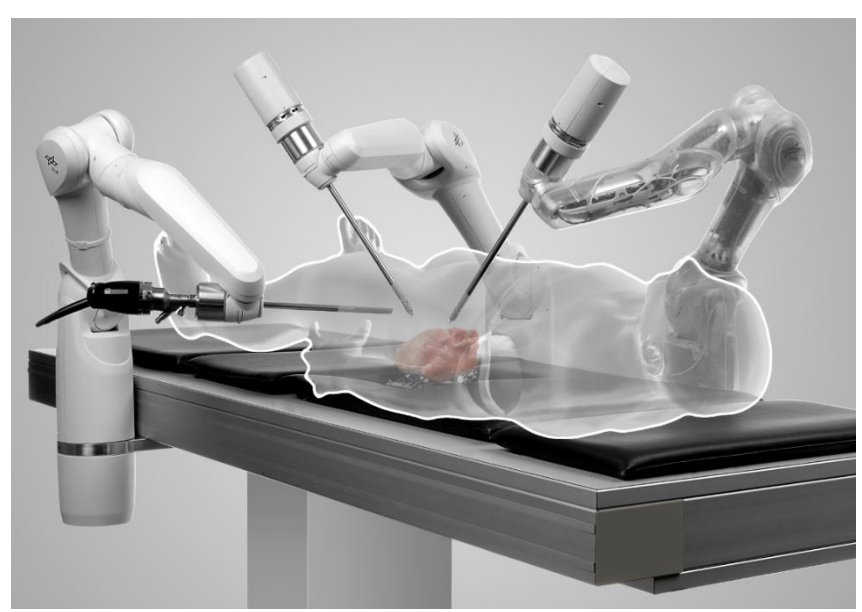




\section{Avatera System}

The Avatera system (Figure 7) is a master-slave robotic platform which has been in development since 2011 as a joint venture between Avateramedical (Jena, Germany) and Force Dimension (Nyon, Switzerland). It received European CE Mark approval in 2019. It offers a seatedclosed console, with 4 robotic arms mounted on a single cart, forceps-like handles with haptic feedback, singleuse $5 \mathrm{~mm}$ instruments with 7 DOF, and an HD-3D camera. Unique features include the absence of external fans, which decreases the noise level, and a space-saving compact design. No clinical data on the use of the Avatera System have been published to date.

\section{FIGURE 7.}

Avatera System

(Credit: Avateramedical)

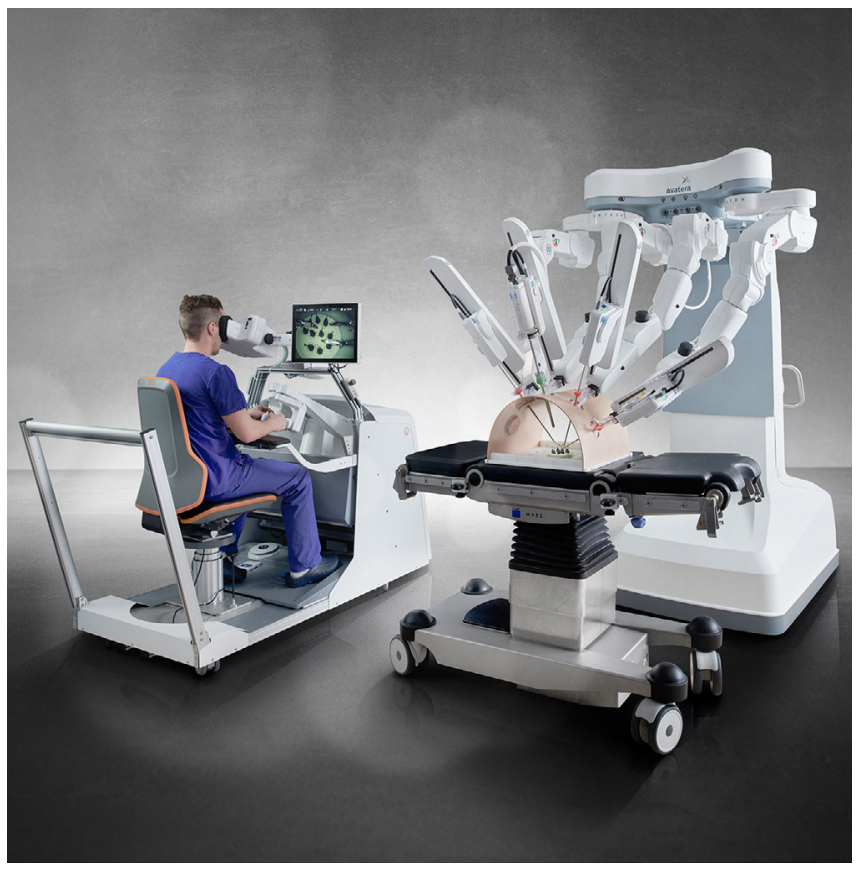

\section{Hugo RAS System}

The Hugo RAS system is a master-slave robotic platform created by Medtronic, following the acquisition of German-based robotic system MiroSurge as part of the acquisition of Covidien in 2014. It does not currently have regulatory approval in Europe. The surgeon console employs a seated, semi-open design, requiring 3 -D glasses with HD visualization. Each robotic arm is attached to an individualized cart, allowing robotic arms to be split up and used for different procedures, each with 7 DOF. Currently, no pre-clinical or clinical data are available.

\section{Ottava}

Ottava, previously the Verb master-slave robotic platform, is in development, and is a joint venture by Ethicon, Johnson \& Johnson (J \& J), and Verily (a life sciences research organization within Google, Inc). In addition, in 2019, J \& J acquired Auris Health who had developed the MONARCH platform for endoscopy. The platform does not have any regulatory body approval. Initial reports suggest that there may be 6 robotic arms directly attached to the operating table, but there is no credible information about the robotic platform currently available and no identified pre-clinical or clinical data on the Ottava platform.

\section{Hinotori}

The Hinotori master-slave surgical platform was developed through a joint venture begun in 2013 between 2 Japanese companies, Kawasaki Heavy industries, Ltd and Sysmex Company. The Hinotori surgical system, which received Japanese regulatory approval in August 2020, is advertised as an easy docking system, with 4 robotic arms attached to the cart, and instruments with 8 DOF. The surgeon wears polarized glasses, using a semi-open console with a microscope-like ocular lens. Although a simulation system is in development for use on this platform, no pre-clinical or clinical data have been published to date.

\section{Conclusions}

We provide a scoping review of identified masterslave robotic surgical platforms with applications in urology. Despite increasing use of these platforms in surgery, there is still a paucity of published literature comparing different robotic platforms, many of which are still awaiting regulatory approval. Cost comparisons are currently not possible as many of these emerging platforms are not yet commercially available. Further research with direct comparisons of robotic platforms will be necessary to assess clinical outcomes, surgeon preference, and economic and environmental sustainability. To this point, the Intuitive Surgical da Vinci series has dominated the field, but this will likely change as other systems are approved. 


\section{References}

1. Challacombe BJ, Khan MS, Murphy D, Dasgupta P. The history of robotics in urology. World J Urol.2006;24(2):120-127. doi: 10.1007/ s00345-006-0067-1

2. Choussein S, Srouji SS, Farland LV, Wietsma A, Missmer SA, Hollis $\mathrm{M}$, et al. Robotic assistance confers ambidexterity to laparoscopic surgeons. J Minim Invasive Gynecol.2018;25(1):76-83. doi: 10.1016/j. jmig.2017.07.010.

3. Atug F, Castle EP, Woods M, Davis R, Thomas R. Robotics in urologic surgery: an evolving new technology. Int J Urol.2006;13(7):857-863. doi: 10.1111/j.1442-2042.2006.01428.x

4. Abiri A, Pensa J, Tao A, Ma J, Juo YY, Askari SJ, et al. Multi-modal haptic feedback for grip force reduction in robotic surgery. Sci Rep.2019;9(1):5016. doi: 10.1038/s41598-019-40821-1.

5. Seeliger B, Diana M, Ruurda JP, Konstantinidis KM, Marescaux J, Swanstrom LL. Enabling single-site laparoscopy: the SPORT platform. Surg Endosc.2019;33(11):3696-3703. doi: 10.1007/ s00464-018-06658-x

6. Gaboardi F, Pini G, Suardi N, Smelzo S, Passaretti G, Rosso M, et al. Robotic laparoendoscopic single-site (r-LESS) radical prostatectomy: IDEAL phase 1. Eur Urol.(Supp/)2016;15 (3):eV12.

7. Billah MS, Stifelman M, Munver R, Tsui J, Lovallo G, Ahmed M. Single port robotic assisted reconstructive urologic surgery-with the da Vinci SP surgical system. Trans/ Androl Urol.2020;9(2):870-878. doi: 10.21037/tau.2020.01.06

8. Munn Z, Peters MDJ, Stern C, Tufanaru C, McArthur A, Aromataris E. Systematic review or scoping review? Guidance for authors when choosing between a systematic or scoping review approach. BMC Med Res Methodol.2018;18(1):143.https://doi.org/10.1186/ s12874-018-0611-x

9. Moher D, Liberati A, Tetzlaff J, Altman DG, Group P. Preferred reporting items for systematic reviews and meta-analyses: the PRISMA statement. Int J Surg.2010;8(5):336-341. doi: 10.1016/j. ijsu.2010.02.007

10. Page MJ, McKenzie JE, Bossuyt PM, Boutron I, Hoffmann TC, Mulrow CD, et al. The PRISMA 2020 statement: an updated guideline for reporting systematic reviews. Int J Surg.2021;88:105906. https://doi. org/10.1016/j.ijsu.2021.105906

11. Goonewardene SS, Cahill D. The da Vinci Xi and robotic radical prostatectomy-an evolution in learning and technique. J Robot Surg.2017;11(2):111-113. doi: 10.1007/s11701-016-0620-x

12. Patel MN, Hemal AK. Does advancing technology improve outcomes? Comparison of the da Vinci Standard/S/Si to the Xi Robotic Platforms during robotic nephroureterectomy. J Endourol.2018;32(2):133-138. doi: 10.1089/end.2017.0477

13. Autorino R, Kaouk JH, Stolzenburg JU, Gill IS, Mottrie A, Tewari A, et al. Current status and future directions of robotic single-site surgery: a systematic review. Eur Urol.2013;63(2):266-280. doi: 10.1016/j. eururo.2012.08.028
14. Won Lee J, Arkoncel FR, Rha KH, Choi KH, Yu HS, Chae Y, et al. Urologic robot-assisted laparoendoscopic single-site surgery using a homemade single-port device: a single-center experience of 68 cases. J Endourol.2011;25(9):1481-1485. doi: 10.1089/end.2010.0656

15. Gavazzi A, Belba A, Dasgupta P. Robotic single-port transumbilical radical prostatectomy: our first experience using the gel-port system. BJU Int.2012;(3):130.

16. Kim KH, Song W, Yoon H, Lee DH. Single-port robot-assisted radical prostatectomy with the da Vinci SP system: a single surgeon's experience. Investig Clin Urol.2020;61(2):173-179. doi: 10.4111/ icu.2020.61.2.173

17. Kaouk J, Aminsharifi A, Sawczyn G, Kim S, Wilson CA, Garisto J, et al. Single-port robotic urological surgery using purpose-built single-port surgical system: single-institutional experience with the first 100 cases. Urology.2020;140:77-84. doi: 10.1016/j.urology.2019.11.086

18. Chan ES, Yee CH, Lo KL, Chan CK, Hou SM, Ng CF. Sidedocking technique for robot-assisted urologic pelvic surgery. Urology.2013;82(6):1300-1303. doi: 10.1016/j.urology.2013.08.017

19. Chan SY, Hou SM, Wong WS, Ng CF. Robotic urological surgery: prospects for Hong Kong. Surg Pract.2007;11(4):154-158.

20. Park SY, Jeong W, Choi YD, Chung BH, Hong SJ, Rha KH. Yonsei experience in robotic urologic surgery - Application in various urological procedures. Yonsei Med J.2008;49(6):897-900. doi: 10.3349/ymj.2008.49.6.897

21. Fareed K, Zaytoun OM, Autorino R, White WM, Crouzet S, Yakoubi R, et al. Robotic single port suprapubic transvesical enucleation of the prostate (R-STEP): initial experience. BJU Int.2012;110(5):732-737. doi: 10.1111/j.1464-410X.2012.10954.x

22. Yuh B, Yu X, Raytis J, Lew M, Fong Y, Lau C. Use of a mobile towerbased robot - the initial Xi robot experience in surgical oncology. J Surg Oncol.2016;113(1):5-7. https://doi.org/10.1002/jso.24094

23. Osmonov D, Prell F, Kalz A, Junemann KP. VS-1-9 Da Vinci robot-assisted vasovasostomy and vasoepididymostomy. J Sex Med.2020;17(6 Suppl 2):S149.

24. Mah L, Noel O, Rothschild J, Dall'Era M, Canvasser N. Right robotic intracorporeal ileal ureter with single-position port placement using da Vinci Xi. J Urol.2019;201(4 Suppl 1):e401.

25. Garisto J, Bertolo R, Kaouk J. Transperineal Approach for intracorporeal ileal conduit urinary diversion using a purpose-built single-port robotic system: step-by-step. Urology.2018;122:179-184. doi: 10.1016/j. urology.2018.08.019

26. Paradise HJ, Huang GO, Elizondo Saenz RA, Baek M, Koh CJ. Robotassisted laparoscopic pyeloplasty in infants using 5-mm instruments. J Pediatr Urol.2017 Apr;13(2):221-222.doi: 10.1016/j.jpurol.2016.12.011

27. Kang SK, Jang WS, Kim SW, Kim SH, Han SW, Lee YS. Robotassisted laparoscopic single-port pyeloplasty using the da Vinci $\mathrm{SP}{ }^{\circledR}$ system: initial experience with a pediatric patient. J Pediatr Urol.2019;15(5):576-577. doi: 10.1016/j.jpurol.2019.08.003 
28. Ahmed K, Ibrahim A, Wang TT, Khan N, Challacombe B, Khan MS, et al. Assessing the cost effectiveness of robotics in urological surgery - a systematic review. BJU Int.2012;110(10):1544-1556. doi: 10.1111/j.1464-410X.2012.11015.x

29. Bozzini G, Gidaro S, Taverna G. Robot-assisted laparoscopic partial nephrectomy with the ALF-X robot on pig models. Eur Urol.2016;69(2):376-377. doi: 10.1016/j.eururo.2015.08.031

30. Falavolti C, Gidaro S, Ruiz E, Altobelli E, Stark M, Ravasio G, et al. Experimental nephrectomies using a novel telesurgical system: (The Telelap ALF-X)-a pilot study. Surg Technol Int.2014;25:37-41.

31. Brodie A, Vasdev N. The future of robotic surgery. Ann R Coll Surg Engl.2018;100(Suppl 7):4-13. doi: 10.1308/rcsann.supp2.4

32. deBeche-Adams T, Eubanks WS, de la Fuente SG. Early experience with the Senhance(R)-laparoscopic/robotic platform in the US. J Robot Surg.2019;13(2):357-359. doi: 10.1007/s11701-018-0893-3

33. Kaštelan Ž, Knežević N, Hudolin T, Kuliš T, Penezić L, Goluža E, et al. Extraperitoneal radical prostatectomy with the Senhance Surgical System robotic platform. Croat Med J.2019;60(6):556-559. doi: 10.3325/cmj.2019.60.556

34. Kastelan Z, Hudolin T, Kulis T, Penezic L, Gidaro S, Bakula M, et al. Extraperitoneal radical prostatectomy with the Senhance Robotic Platform: first 40 cases. Eur Urol.2020;78(6):932-934. doi: 10.1016/j. eururo.2020.07.012

35. Samalavicius NE, Janusonis V, Siaulys R, Jasenas M, Deduchovas 0 , Venckus $R$, et al. Robotic surgery using Senhance ${ }^{\circledR}$ robotic platform: single center experience with first 100 cases. J Robot Surg.2020;14(2):371-376. doi: 10.1007/s11701-019-01000-6

36. Kastelan Z, Hudolin T, Kulis T, Knezevic N, Penezic L, Maric M, et al. Upper urinary tract surgery and radical prostatectomy with Senhance ${ }^{\circledR}$ robotic system: single center experience-first 100 cases. Int J Med Robot.2021 Aug;17(4):e2269. doi: 10.1002/rcs.2269
37. Haig F, Medeiros ACB, Chitty K, Slack M. Usability assessment of Versius, a new robot-assisted surgical device for use in minimal access surgery. BMJ Surg Interv Health Technol.2020;2:e000028. doi:10.1136/ bmjsit-2019-000028

38. Thomas BC, Slack M, Hussain M, Barber N, Pradhan A, Dinneen E, et al. Preclinical evaluation of the Versius Surgical System, a new robot-assisted surgical device for use in minimal access renal and prostate surgery. Eur Urol Focus.2021;7(2):444-452. doi: 10.1016/j. euf.2020.01.011

39. Kelkar D, Borse MA, Godbole GP, Kurlekar U, Slack M. Interim safety analysis of the first-in-human clinical trial of the Versius surgical system, a new robot-assisted device for use in minimal access surgery. Surg Endosc.2020. doi: 10.1007/s00464-020-08014-4

40. Kim DK, Park DW, Rha KH. Robot-assisted partial nephrectomy with the REVO-I Robot Platform in porcine models. Eur Urol.2016;69(3):541542. doi: 10.1016/j.eururo.2015.11.024

41. Chang KD, Abdel Raheem A, Choi YD, Chung BH, Rha KH. Retziussparing robot-assisted radical prostatectomy using the Revo-i robotic surgical system: surgical technique and results of the first human trial. BJU Int.2018;122(3):441-448. https://doi.org/10.1111/bju.14245

42. Abdel Raheem A, Troya IS, Kim DK, Kim SH, Won PD, Joon PS, et al. Robot-assisted Fallopian tube transection and anastomosis using the new REV0-I robotic surgical system: feasibility in a chronic porcine model. BJU Int.2016;118(4):604-609. doi: 10.1111/bju.13517

43. Hagn U, Konietschke R, Tobergte A, Nickl M, Jorg S, Kubler B, et al. DLR MiroSurge: a versatile system for research in endoscopic telesurgery. Int J Comput Assist Radiol Surg.2010;5(2):183-193. doi: 10.1007/s11548-009-0372-4 